\title{
Astronomy Books in Spanish
}

Julieta Fierro, Instituto de Astronomía, UNAM, Apt 70 264, México DF 04510, México

Great cultures have created language. They have discovered its strength among other reasons for education. For a long time the Bible was one of the few books available in western culture, its influence is beyond any doubt. Many developing nations have no science books in their mother tongue. They might carry a few translations but these do not convey the local culture so it is harder for students to grasp the concepts and to build on what they know. Books, even if they are extremely simple, should be written in local languages because that will facilitate the conveying of knowledge and the creation of scientific culture. In the books examples that pertain to every day local life must be given, in particular examples that have to do with women. Women play a central role in developing nations by child bearing; if they become literate they will influence enormously the quality of their children's education, in particular their science comprehension. In México a collection that includes astronomy books has recently been edited by the National Council for Culture and Arts. The books are small and light, which encourages middle-school students to carry them around and read them while traveling in public transportation, such as the subway. Every other page is a new subject, that carries illustrations, abstracts and conclusions. The astronomy books are on search for extraterrestrial life, the stars and the universe. These books are distributed nation-wide and are inexpensive. They have been written by Mexican astronomers.

\section{Teaching of Astronomy in India}

Mandayam N. Anandaram, Physics Department Bangalore University, Bangalore 560065 , India

Here I will describe the inclusion of astronomy and astrophysics in College level courses of Bangalore University. I will describe the role of the Inter University Center for Astronomy and Astrophysics (IUCAA) at Pune in making available instruments such as photometers and CCD cameras at low cost to aid teaching of astronomy as well as the running of a large number of training programmes for teachers and students. I will also describe some outstanding problems and suggested solutions.

\section{Summer Schools for European Teachers}

Rosa M. Ros, Department of Applied Mathematics, Technological University of Catalonia, Jordi Girona 1-3, Modul C3, 08034 Barcelona, Spain

The Summer Schools have been organised by the European Association for Astronomy Education (EAAE) for European teachers. The first was organised 